\title{
Stock Prices' Variability around Earnings Announcement Dates at Karachi Stock Exchange
}

\author{
Muhammad Azeem Qureshi, ${ }^{1}$ Ali Abdullah, ${ }^{2}$ and Muhammad Imdadullah ${ }^{2}$ \\ ${ }^{1}$ School of Business, Oslo and Akershus University College of Applied Sciences, Oslo 0130, Norway \\ ${ }^{2}$ Institute of Management Sciences, Bahauddin Zakariya University, Multan 60800, Pakistan \\ Correspondence should be addressed to Muhammad Azeem Qureshi, muhammad-azeem.qureshi@hioa.no
}

Received 26 March 2012; Accepted 22 July 2012

Academic Editor: Perry Sadorsky

Copyright (C) 2012 Muhammad Azeem Qureshi et al. This is an open access article distributed under the Creative Commons Attribution License, which permits unrestricted use, distribution, and reproduction in any medium, provided the original work is properly cited.

\begin{abstract}
The purpose of this study is to investigate how earnings announcement event affects stock returns at Karachi Stock Exchange (KSE). For this purpose we use the KSE-100 Index as our sample. We use the CAR Analysis to analyze the impact of earnings announcement over the stock returns around announcement dates. Our results suggest that KSE experiences abnormal stock returns around earnings announcement dates for the overall market and for different categories which indicate that efficient market hypothesis does not hold in Pakistani market and point out the presence of informational dissemination inefficiencies in the market.
\end{abstract}

\section{Introduction}

Changes in stock prices constitute a key component of stocks returns and, hence important for the investors, practitioners and researchers alike. A number of factors affect stock prices in a number of different forms. One of them can be a certain event which may affect trading activities at the stock exchange and consequently stock prices. Earnings announcement is one such event, and its information content is likely to trigger response of the market participants considering their anticipations [1]. Resultantly, a different trading pattern is likely to emerge in the market around earnings announcement event.

Assuming information symmetry put forward by the efficient market hypothesis (EMH), information content of the earnings announcement may not have any impact on the normal trading and prices pattern. However, hypothesizing that EMH does not hold, we are likely to observe trading and prices anomalies around earnings announcement event. Earnings announcement premium is well documented for the developed stock exchanges in the world but we do not have such a study for Karachi Stock Exchange (KSE). Our objective is to examine return anomalies around earnings announcement dates at KSE.
We organize rest of this paper as follows: we review the prior relevant researches in Section 2, we describe the research method and the data in Section 3, in Section 4 we present our results and analysis, and in Section 5 we put forward our findings and conclusions.

\section{Literature Review}

Since the advent of EMH [2], we observe its thorough empirical scrutiny across the globe as to what extent markets ensure symmetric information to all market participants and conform to EMH. Earning is perceived to be an important indicator of current and future state of the organization and the premier information in financial statements. Availability of this information to the market participants is likely to cause market response for which researchers have provided empirical evidence of an association between accounting information and security returns, and such a relation becomes significant at the time of earnings announcement [1], which is the primary focus of this study.

A lot of uncertainty is associated with earnings announcement, an important event for the market as its information content vis-à-vis expectations of the market participants gives rise to volatility which gradually increases 
till the announcement date and then falls to its normal level. In the case of positive news, this uncertainty comes to its normal level in the lesser period as compared to the case of negative news [3]. Asymmetric information among the market participants reduces after the earnings announcement implying new information content in them [4]. Studies show that different investors have different levels of information in the market, and private information is gradually revealed giving rise to the liquidity in the stock market before the release of earnings [5]. Investors seek to find some private information before the official disclosure of earnings, and information asymmetry in the market gives the informed market participants a chance to move according to their interest, and it gives high volatility to the stock prices in the market according to the expected content of the earnings disclosure [6].

Trading volume and trading practices depict the information held by the speculators at the stock market and help to predict the stock prices in the following days [7], where there is a kind of association between the large volume increase and a large price change [8]. The evidence of anomalies in stock prices with the release of income report shows that information is reflected in the income numbers [1]. The variability in the stock returns around earnings announcement date is larger as compared to that in nonannouncement period indicating new information presented. Moreover, there is a reduction in price volatility after the announcement consequence of reduced information asymmetry and uncertainty [9]. Optimism in the preannouncement period may increase demand to give stock price hype during these days, but rationalization in the postannouncement period brings the price to even lower level in ten days window around the announcement date, and average abnormal returns remain economically large [10]. Accounting and financial reporting and their information content play a key role in stock price reaction where announcement about increase in earnings generates positive reaction in stock price and vice versa [11].

The stock returns and trading volume tend to be positively correlated, but unequal distribution of information as well as the optimistic attitude of investors during preannouncement period gives a rise to trading volume and stock prices based on the past performance of the stocks during announcement periods [12]. However, there is a significant impact of firm size over this specific behavior where the stocks of relatively small firms show large, positive abnormal returns around earnings announcement dates due to information asymmetry, and large firms do not show significant impact in returns around these dates [13]. This clearly suggests more information asymmetry during preannouncement period as compared to postannouncement period, which is associated more with small firms exposed to lesser market monitoring and most of the information about them is revealed through their official disclosures $[14,15]$.

\section{Methodology and Data}

The core objective of this study is to investigate the movement of share price around earnings announcement dates in Pakistani market. For this purpose we select the KSE being the largest and the oldest market of the country and use KSE-100 Index as our target sample. This index is generally considered a true representative of the KSE due to its systematic and dynamic composition.

We use secondary data of KSE to collect the data about the stock prices and the date of earnings announcement for a five years' period from 2005 to 2009 . We collect the prices in an 11-day event window, that is, from five trading days before the earnings announcement to the five trading days after the announcement. The date of results announcement is taken as day 0. We use the Mean Adjusted Model [16] to examine the impact of the earnings announcement on the price behavior of stocks. We examine the impact of the earnings releases on the stock prices which is depicted in the abnormal or excess return as compared to any other random day selected.

Assuming informational symmetry in an efficient market, the prices behavior of stocks should be same as in all days including days around earnings announcement. However, any deviation from this hypothesized scenario will yield abnormal returns (AR) as measured by (1):

$$
\mathrm{AR}_{j, t}=R_{j, t}-E\left(R_{j, t}\right),
$$

where $t$ is the trading day while $j$ denotes the firm. We denote the 11-day event window as $t=-5,-4,-3,-2,-1,0$, $1,2,3,4,5$. We estimate expected return from a 90-day period before the event period, that is, $t=-95, \ldots,-6$, and use rate of change and not the absolute values of prices for level ground comparison. We calculate the average abnormal returns in the event period by using (2):

$$
\mathrm{AR}_{t}=\frac{1}{N} \sum_{i=1}^{n} \mathrm{AR}_{j, t},
$$

where $N$ is the number of firms in our sample. We then calculate the cumulative abnormal returns (CARs) by adding the average abnormal returns over the days in the event window. Equation (3) presents CAR for each firm $j$ from the day $K$ to day $L$ :

$$
\mathrm{CAR}_{j, K, L}=\sum_{t=K}^{L} \mathrm{AR}_{j, t} .
$$

Equation (4) depicts our formulation for the average CAR:

$$
\mathrm{CAR}_{K, L}=\frac{1}{N} \sum \mathrm{CAR}_{j, K, L} .
$$

We choose to measure the existence of two phenomena, that is, the existence of any abnormal return and the change in the abnormal returns during the event window. Our null hypothesis to check the existence of abnormal return is "Average abnormal return on any day in the event window is equal to zero."

We use test statistic, ratio of the average abnormal return on the given day in the window to its standard deviation, given by (5).

$$
t=\frac{\mathrm{AR}_{t}}{\mathrm{SD}\left(\mathrm{AR}_{t}\right)} .
$$


TABLE 1: Abnormal returns around earnings announcement.

\begin{tabular}{lccc}
\hline Day & AR & $\begin{array}{c}\text { Cumulated Abnormal Returns } \\
(\text { CAR })\end{array}$ & $\begin{array}{c}t \text {-statistic } \\
\text { for AR }\end{array}$ \\
\hline-5 & 0.0572 & 0.0573 & 2.4535 \\
-4 & 0.0556 & 0.1129 & 2.2542 \\
-3 & 0.0622 & 0.1752 & 2.3102 \\
-2 & 0.0677 & 0.2428 & 2.4183 \\
-1 & 0.0664 & 0.3092 & 2.1180 \\
0 & 0.0657 & 0.3750 & 2.1156 \\
1 & 0.0462 & 0.4212 & 1.6614 \\
2 & 0.0549 & 0.4761 & 1.8117 \\
3 & 0.0654 & 0.5415 & 1.7813 \\
4 & 0.0658 & 0.6073 & 1.9119 \\
5 & 0.0669 & 0.6741 & 1.9032 \\
& & CAR-5,1 $=0.4212$ & \\
& & $t$-statistic $=2.0720$ & \\
\hline
\end{tabular}

After identification of abnormal return we identify and measure if there is any change in the abnormal return during the window due to earnings announcement. To do so, we calculate the $t$-statistic which is the ratio of $\mathrm{CAR}_{K, L}$ to standard deviation. We use (6) to calculate $t$-statistic for $\mathrm{CAR}_{K, L}$ :

$$
t_{\mathrm{CAR}_{K, L}}=\frac{\mathrm{CAR}_{K, L}}{\mathrm{SD}\left(\mathrm{CAR}_{K, L}\right)} .
$$

\section{Results and Analysis}

To identify and analyze the impact of earnings announcement on share prices we divide our sample, KSE-100 Index, in manufacturing and services companies, foreign and domestic companies, and also small-, medium-, and largesized companies.

4.1. Overall Sample. First, we analyze the sample performance as a whole irrespective of its categorization. Table 1 depicts the AR and CAR in the event window. Results show that there are significant abnormal returns in the whole event window, that is, the days surrounding earnings announcements. Furthermore, $t$-statistic for the CAR shows that these abnormal returns are due to the announcement of earnings depicting a significant impact of earnings on stock prices and unequal distribution of information in the market. It tells about the speculations and access of some traders to the private information. Pattern in the abnormal returns in the event window is also interesting. Abnormal returns move upwards in the days before the announcement of financial results while they move downwards on the day just after the announcement has been made conforming the earlier studies [9]; however we observe a pattern, maybe unique to KSE, that after a decline the returns again start moving upwards.

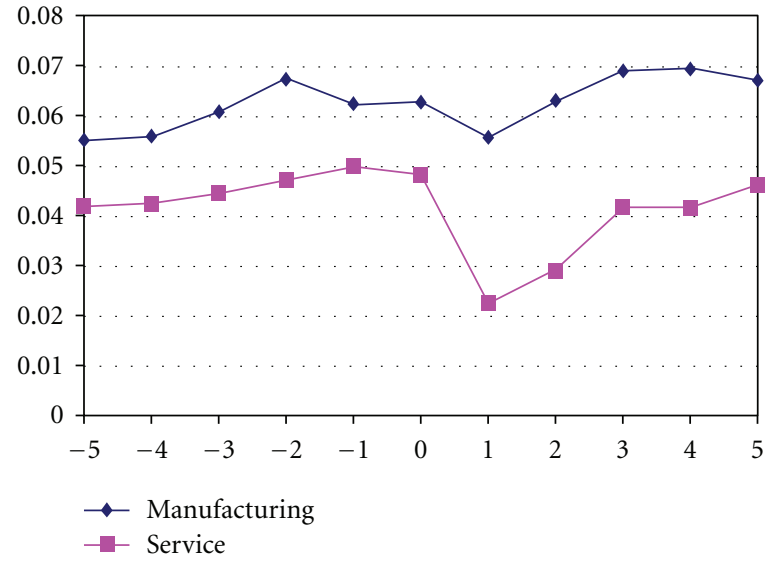

FIGURE 1: Abnormal returns around earnings announcement in manufacturing/service companies.

4.2. Manufacturing and Services Companies. The rationale behind the study of the firms on the basis of type of the industry is simple. Recent years have seen a growing interest of investors in services companies at KSE which we assume may have reduced information asymmetry about these companies as compared to their manufacturing counterparts affecting their earnings announcement premium. Table 2 presents AR and CAR of this categorization.

Table 2 suggests that prices react in an abnormal way during the earnings release days irrespective of the industry classification which we depict in Figure 1, which shows that the extent of these abnormalities differs in the two sectors. We observe higher abnormal returns in manufacturing sector in the event window. Service companies with their professional ownership structures, lean, and transparent management structures offer lesser surprises for the attentive and vigilant investors and provide less abnormality in the prices due to increasing customer interest in the activities and financial performance of the service companies due to their better yield during recent past years.

4.3. Domestic and Foreign Companies. Following the logic of Section 4.2, we analyze our sample on the basis of their ownership. In the past few years, foreign companies have gained lot of attention from investors that may have reduced information asymmetry in the market place which may be prevalent in case of their domestic counterparts affecting their stock price response during earnings announcement period which we present in Table 3.

Table 3 and Figure 2 show that there are abnormalities in the share prices in both foreign and domestic companies. However, we observe quite a higher abnormal return for foreign companies in the event window as compared to their domestic counterparts. Contrary to common observation, our results clearly suggest that foreign companies maintain quite a high level of information asymmetry in the market place despite increased interest of the market participants. The earnings disclosure as such triggers higher abnormal returns. 
TABLE 4: Abnormal returns around earnings announcement in small/medium/large companies.

\begin{tabular}{|c|c|c|c|c|c|c|}
\hline \multirow[b]{2}{*}{ Day } & \multicolumn{2}{|c|}{ Small companies } & \multicolumn{2}{|c|}{ Medium companies } & \multicolumn{2}{|c|}{ Large companies } \\
\hline & $\mathrm{AR}$ & $\begin{array}{c}\text { Cumulative Abnormal Returns } \\
\text { (CAR) }\end{array}$ & $\mathrm{AR}$ & $\begin{array}{c}\text { Cumulative Abnormal Returns } \\
\text { (CAR) }\end{array}$ & $\mathrm{AR}$ & $\begin{array}{l}\text { Cumulative Abnormal Returns } \\
\text { (CAR) }\end{array}$ \\
\hline-5 & 0.1040 & 0.1040 & 0.0433 & 0.0433 & 0.0234 & 0.0234 \\
\hline-4 & 0.1003 & 0.2043 & 0.0390 & 0.0822 & 0.0269 & 0.0511 \\
\hline-3 & 0.1177 & 0.3219 & 0.0393 & 0.1215 & 0.0318 & 0.0828 \\
\hline-2 & 0.1231 & 0.4450 & 0.0453 & 0.1668 & 0.0358 & 0.1186 \\
\hline-1 & 0.1164 & 0.5614 & 0.0467 & 0.2136 & 0.0346 & 0.1532 \\
\hline 0 & 0.1261 & 0.6875 & 0.0397 & 0.2533 & 0.0353 & 0.1885 \\
\hline 1 & 0.1175 & 0.8050 & 0.0409 & 0.2942 & 0.0172 & 0.2057 \\
\hline 2 & 0.1174 & 0.9225 & 0.0525 & 0.3467 & 0.0287 & 0.2344 \\
\hline 3 & 0.1120 & 1.0345 & 0.0458 & 0.3925 & 0.0419 & 0.2763 \\
\hline 4 & 0.1191 & 1.1536 & 0.0384 & 0.4309 & 0.0471 & 0.3234 \\
\hline 5 & 0.1186 & 1.2722 & 0.0391 & 0.4700 & 0.0495 & 0.3729 \\
\hline \multicolumn{3}{|c|}{$\mathrm{CAR}_{5,1}=0.8050$} & \multicolumn{2}{|c|}{$\mathrm{CAR}_{5,1}=0.2942$} & \multicolumn{2}{|c|}{$\mathrm{CAR}_{5,1}=0.2057$} \\
\hline \multicolumn{3}{|c|}{$t$-statistic $=2.0576$} & \multicolumn{2}{|c|}{$t$-statistic $=2.0400$} & \multicolumn{2}{|c|}{$t$-statistic $=1.8292$} \\
\hline
\end{tabular}

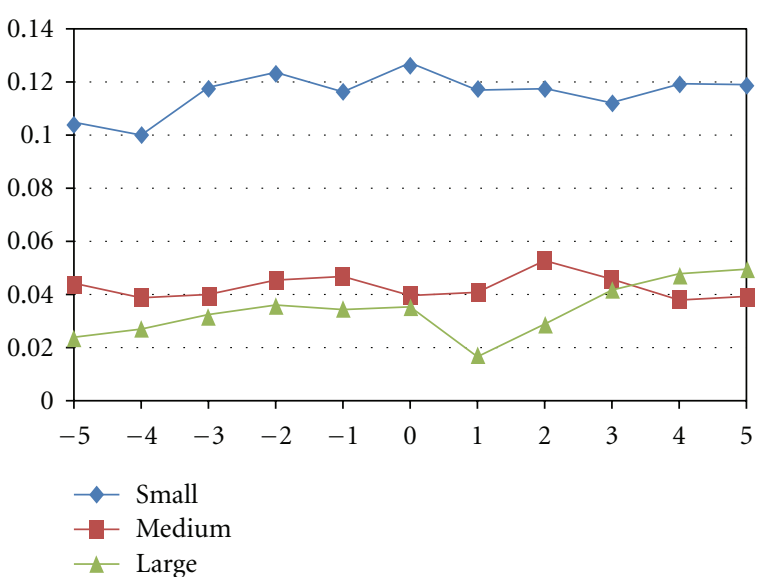

Figure 3: Abnormal returns around earnings announcement in small/medium/large companies.

only in the initial and the final days of event window. The large companies not only have lowest abnormal returns compared to other two categories, but also these returns are significant only on the days before the announcement.

\section{Findings and Conclusion}

Information plays an important role in determining stock returns. The EMH assumes symmetric information, but prevalent asymmetric information in the market place plays a key role to give advantage to better informed market participants. In this context, earnings announcement helps reduce information asymmetry and uncertainty surrounding it.

We investigate how earnings announcement event affects stock returns at KSE analyzing KSE-100 Index. Our results for entire sample conform to the earlier studies suggesting that markets experience abnormal stock returns around earnings announcement dates. Prices behave significantly different around this particular event confirming that these changes are due to the announcement of earnings. The EMH suggests that there should be no significant change in the stock prices around such event, and prices should react in a normal way. However, our results of the overall market and different categories show that there are anomalies in the prices around these dates which indicate that EMH does not hold in Pakistani market and point out the presence of informational dissemination inefficiencies in the market.

Considering the industry classification, we find that manufacturing companies experience more changes in the prices around earnings announcements as compared to the service companies. Increased interest of the market participants and relative lesser informational asymmetry maintained by service companies result in lesser earnings surprise for the market. From ownership perspective, foreign companies depict higher information asymmetry and high abnormal returns around earnings announcement. Moreover, smaller companies depict high abnormal returns during earnings announcement period as compared to their larger counterparts. The extent of return abnormality around earnings announcement event varies depending upon the classification but its presence is pervasive.

\section{References}

[1] R. Ball and P. Brown, "An empirucal evaluation of accounting income numbers," Journal of Accounting Research, vol. 6, pp. 159-178, 1968.

[2] E. F. Fama, "Efficient capital markets: a review of theory and empirical work," Journal of Finance, vol. 25, no. 2, pp. 383-417, 1970.

[3] D. Isakov and C. Pérignon, "Evolution of market uncertainty around earnings announcements," Journal of Banking \& Finance, vol. 25, no. 9, pp. 1769-1788, 2001.

[4] C. M. C. Lee, "Earnings news and small traders. An intraday analysis," Journal of Accounting and Economics, vol. 15, no. 2-3, pp. 265-302, 1992. 
[5] J. W. Cho, "Earnings announcements, private information, and strategic informed trading," Journal of Financial Intermediation, vol. 16, no. 1, pp. 117-149, 2007.

[6] M. Bagnoli, M. D. Beneish, and S. G. Watts, "Whisper forecasts of quarterly earnings per share," Journal of Accounting and Economics, vol. 28, no. 1, pp. 27-50, 1999.

[7] L. Blume, D. Easley, and M. O’Hara, "Market statistics and technical analysis: the role of volume," Journal of Finance, vol. 49, no. 1, pp. 153-181, 1994.

[8] C. C. Ying, "Market prices and volumes of sales," Econometrica, vol. 34, no. 3, pp. 676-685, 1966.

[9] A. Eilifsen, K. K. Henry, and F. Sættem, "Earnings announcements and the variability of stock returns," Scandinavian Journal of Management, vol. 17, no. 2, pp. 187-200, 2001.

[10] B. Trueman, M. H. F. Wong, and X. J. Zhang, "Anomalous stock returns around internet firms earnings announcements," Journal of Accounting and Economics, vol. 34, no. 1-3, pp. 249271, 2003.

[11] D. Su, "Stock price reactions to earnings announcements: evidence from Chinese markets," Review of Financial Economics, vol. 12, no. 3, pp. 271-286, 2003.

[12] O. Lamaont and A. Frazzini, "The earnings announcement premium and trading volume," NBER Working Paper W13090, 2007, http://www.nber.org/papers/w13090.

[13] V. V. Chari, R. Jagannathan, and A. R. Ofer, "Seasonalities in security returns. The case of earnings announcements," Journal of Financial Economics, vol. 21, no. 1, pp. 101-121, 1988.

[14] L. S. Bamber, "The information content of annual earnings releases: a trading volume approach," Journal of Accounting Research, vol. 24, no. 1, pp. 40-56, 1986.

[15] M. Vieru, "The impact of interim earnings announcements on the permanent price effects of trades on the Helsinki stock exchange," Journal of Multinational Financial Management, vol. 12, no. 1, pp. 41-59, 2002.

[16] S. J. Brown and J. B. Warner, "Using daily stock returns. The case of event studies," Journal of Financial Economics, vol. 14, no. 1, pp. 3-31, 1985. 


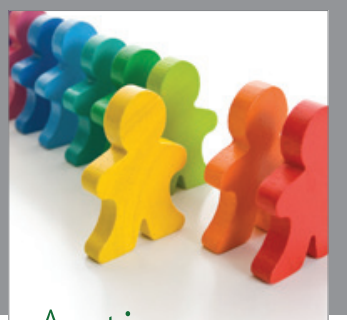

Autism

Research and Treatment
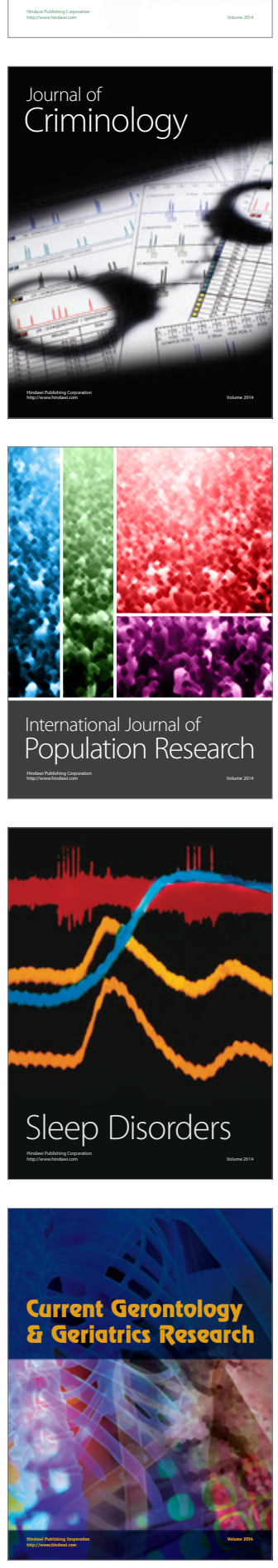
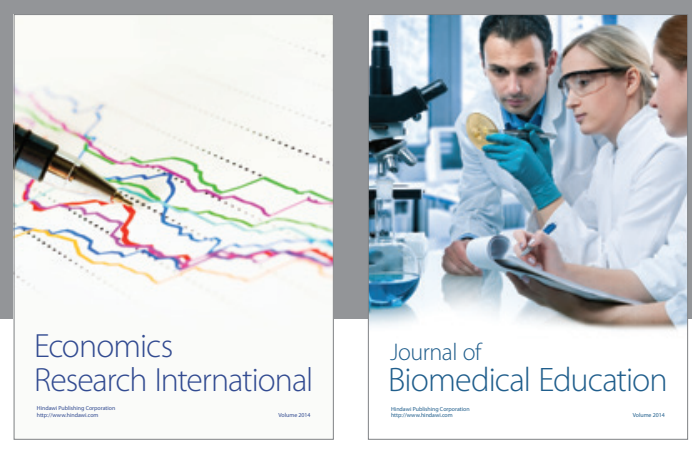

Journal of

Biomedical Education

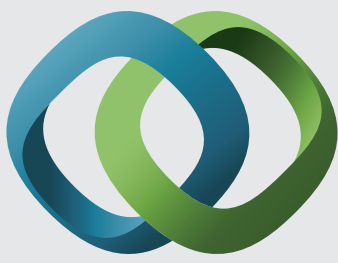

\section{Hindawi}

Submit your manuscripts at

http://www.hindawi.com
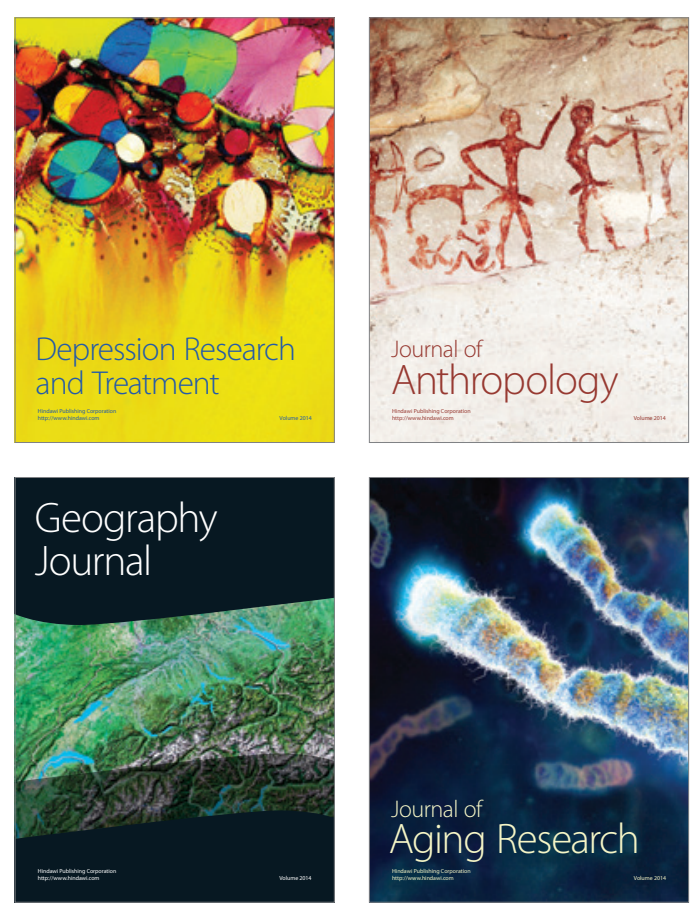

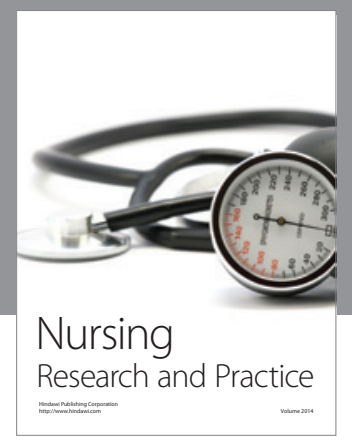

Nursing

Research and Practice

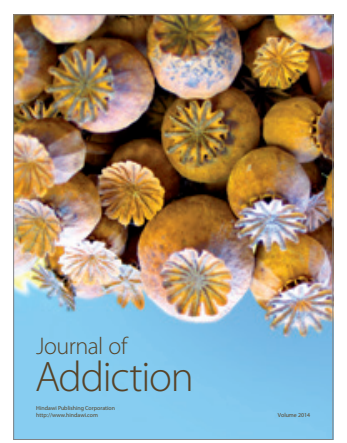

Child Development

Research

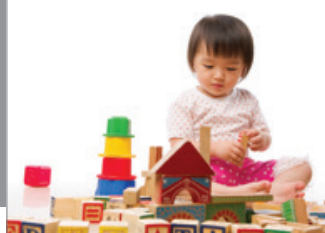

迥
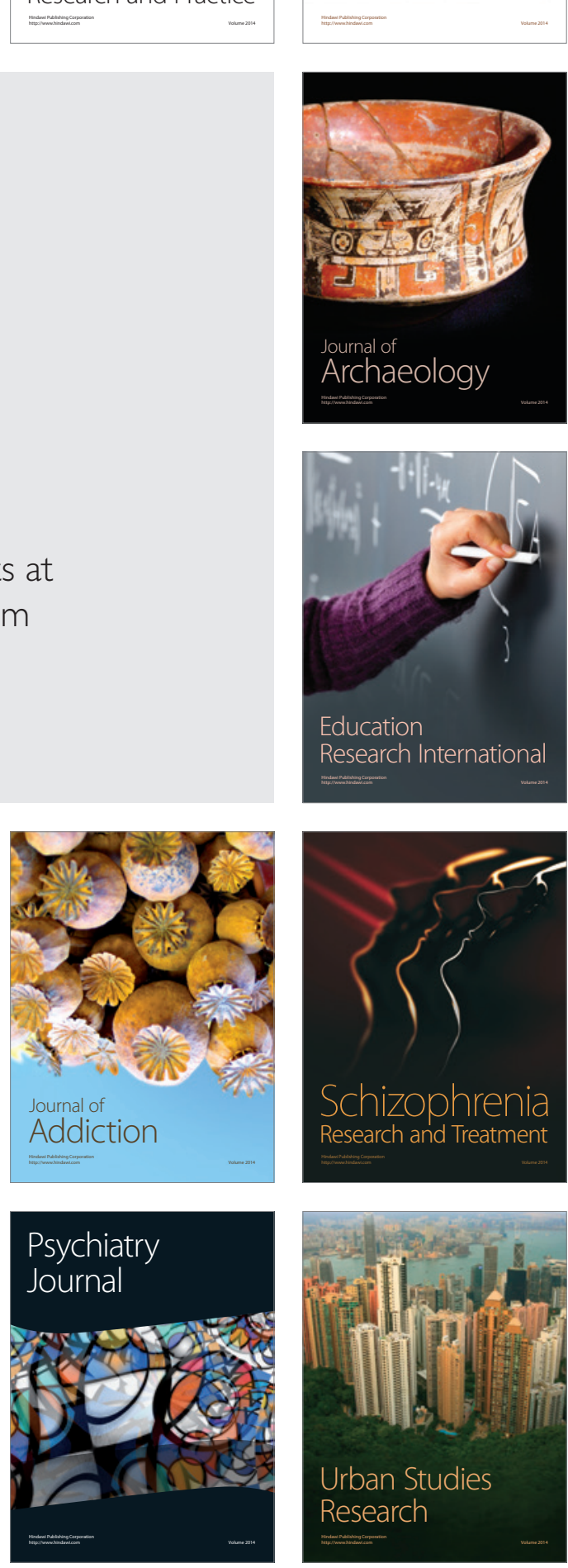